\title{
Climate Change Mitigation and Adaptation - The Centrality Of Carbon Clusters And Creativity In Climate Change Adaptation And Mitigation: A Linguistic Perspective
}

\author{
Peter Makwanya and Elliott Muchena \\ Lecturers in the Department of Languages and Media Studies. Zimbabwe Open University, Zimbabwe.
}

\begin{abstract}
The notion of carbon is quite central to climate change mitigation and adaptation programmes. Although carbon is one of the harmful gases that drive the climate change scourge, it is the lexical creativity around the word carbon that brings out some comic reliefs in a seemingly complex and confusing situation. The word carbon may be modeled around several clusters such as the Moral and Religious Cluster (carbon sinner, carbon guilty or carbon criminal), Dietary Cluster (low-carbon diet, carbon calories), the Financial Cluster (carbon trading, carbon finance or carbon markets) and the Political cluster (carbon neutrality, carbon battle, carbon war).Climate change documents, texts, pamphlets and briefings fall under the descriptive survey (qualitative methodology). Approaches such as Document Analysis, Critical Discourse Analysis and Text Analysis will be used to find the Communicative Functions of these carbon clusters. Interview techniques will be used to probe the policy makers and environmental officials on the contribution of these clusters in adaptation and mitigation programmes. The analytic approaches will be used in relation to ethnography of communication in order to evaluate the socio- economic status, cultural and ethical implications of the society. The ideological orientations of the climate change carbon clusters will be analyzed in relation to the major emitting nations.
\end{abstract}

Key Words: Carbon, Cluster, Mitigation, Adaptation, Ethnography

\section{Background to the Study}

The centrality of carbon in the discourse of climate change is indisputable, both as a harmful and also as a productive gas. The climate change glossary defines carbon dioxide as, a naturally occurring gas, and also a by-product of burning fossil fuels and biomass, as well as land-use changes and other industrial processes. It is the reference gas against which other green house gases are measured and therefore has a global warming potential. Henson (2006:24) cites that, "carbon dioxide, the chief offender, accounts for about 380 of every million molecules in the air, 380 parts per million." Carbon dioxide is both a pollutant and a natural part of the atmosphere, carbon dioxide is produced when fossil fuels are burnt as well as when people and animals breathe and plants decompose. Carbon is the foundation stone and driver of life on our planet (Borchert, 2011). All living things contain carbon but excess of carbon dioxide, which is happening now, means that extra green house gases capture more of the sun's heat which would normally escape into the space. This extra warmth is causing global warming all over the world, global warming in turn causes climate change.

The extra carbon dioxide that man is adding to the atmosphere from burning fossil fuels (coal, oil, and natural gas) is proving too much for natural carbon cycle to deal with. From the start of the industrial revolution in the $18^{\text {th }}$ to the $19^{\text {th }}$ Centuries, coal began to be consumed in ever increasing quantities' to meet the alarming needs of energy (Henson, 2006). The major emitters and drivers of carbon dioxide, who in this case are the industrialized countries such as the USA, UK, Germany, China, Japan, Brazil, Russia, Australia, India, just to name a few, are also the same countries who want to be seen as advocates for less emissions yet they emit more mega-tones of carbon into the atmosphere. The Netherlands Environmental Assessment Agency, MNP, points out that, in 2010, China emitted $22 \%$ of carbon into the atmosphere, USA 21\%, EU countries $11 \%$, Russia $6 \%$, Japan $4 \%$ and the rest of the world emitted 36\%. According to Borchert (2011) the developed countries led by the USA, remain responsible for the greatest emissions of carbon dioxide and other green house gases.

These are the same countries that coined several linguistic discourses and metaphors around the word carbon (lexical creativity) to come up with several carbon clusters and compounds in order to regulate the menace of carbon by giving it a human face, moral aspect, religious, political or economic aspect. The lexical creativity or compounding came up with the following carbon blends that will form the bulky of this research: carbon footprints, carbon sinner, carbon guilty, carbon criminal, low carbon diet, carbon calories, carbon trading, carbon finance, carbon budgets, the list is long. Since it is the human hand that is responsible for carbon emissions around the world, these lexical combinations on carbon are designed to act as corrective measures on the part of the human beings around the globe. Crystal (1991) views these lexical combinations as 'structural ambiguities', a "term used in linguistics to refer to any construction with more than one grammatical 
interpretation in terms of constituents' analysis." There fore, structural ambiguities can also be caused by the omission of a word or words in a structure.

The scientists use several lexical compounding and combinations so as to give emphasis to the activity in question. Dow and Downing (2006) view compounding as a lexical combination of at least two roots such as 'global warming', 'carbon footprint', 'carbon market', 'water harvesting', and 'water accounts'. Related to compounding is a linguistic technique called blending. This is when a word is formed from parts taken from other words. The other technique scientists' use to come up with compound words as suggested by Keller (2000) is studying around lexical creativity around carbon compounds in order to come up with the following examples: carbon budgets, carbon neutrality, carbon credits, carbon assessment, carbon offsetting, carbon management, carbon cycle, carbon footprint, carbon capture, carbon sequestration, low- carbon calories, among others. The idea of sometimes giving carbon human qualities or impersonating it is designed to help shape public or nations' attitudes and perceptions on issues of climate change. In their behavioural attributes, the human beings need to take positive action in order to overcome the listed carbon compounds.

These carbon clusters are not only compounds but metaphors as well. Discourses like carbon footprints, carbon sinner, carbon neutrality, carbon credits or carbon calories are actually metaphors. Metaphor, in general, is about approaching something in terms of some one else (Larkoff and Johnson, 1980). Metaphors are generally persuasive in our everyday language and the way people conceptualize reality. Although metaphors are persuasive in every day life, they are so ordinary 'that we use them unconsciously and automatically, with so little effort that we hardly notice. They are omnipresent: metaphors fuse our thoughts, no matter what we are thinking about' (Larkoff and Turner, 1989: ix).

Metaphors are studied in a variety of disciplines such as philosophy, linguistics, literary studies or psychology. For a very long time, the dominant view of metaphor was that it is the, 'exclusive domain of literary scholars and the odd linguists who are interested in rhetoric and stylistics' (Ungerer and Schmidt, 1996:114). In this view, metaphors are not simply stylistic devices but are a critical component of meaning generation in human communication. Aristotle (cited in Eubanks, 1999), a metaphor is a two part expression; it has two main discursive locations, namely, the place where it has originated and the place to which it has been transferred. According to Black (1962), two expressions, that is, the literal and the metaphorical are equivalent, and the metaphor can then be translated by means of an exhaustive paraphrase. In this view, if we say, 'carbon footprint', the metaphor transforms our simple idea of a human being and his/her footprints but rather more, beyond the statement given in order to consider the permanent marks of the foot prints and their effect on the ground.

\section{Discourse}

The term discourse does not have one stable definition. It has been defined in different ways by authors, researchers and academics from a wide range of fields. In simple terms, discourse is related to the ways people communicate beyond a simple sentence, through either speech or writing. Jorgensen and Phillips (2002) argue that the concept of discourse, though vague, is being used with specific meaning in different contexts. Ibid (2002) present a general idea that, language is structured according to different patterns that people's utterances follow when they take part in different domains of social life. Renkema (2004) explains that the major function of discourse is to offer an explanatory description of the intricate relations between forms of discourse and their communicative functions. From the definitions provided, one would come up with the concept of discourse as, a multiplicity of ways to express information but the manner in which ideas are expressed affect meaning.

In this context, this study seeks to explore the lexical creativity, lexico-grammatical features reflecting discourses of carbon clusters, their communicative functions and the ideological inclinations of the discourses in question, from a linguistic perspective in order to uncover the linguistic aspects that inform the whole issue of carbon clusters and carbon centrality in the climate change discourse.

\section{Methodology}

The methodology is qualitative in nature and it is based on the interpretive philosophy. The data for this study is document based, it is found in scientific journals, magazines, pamphlets, articles and briefings as well as other scientific writings. This is the data that is being critically analyzed so as to come up with their linguistic relevance. The techniques for data gathering are document analysis, text analysis and unstructured interviews. The approach that will dominate the critiquing of scientific documents, texts and other technical forms of writing is Critical Discourse Analysis (CDA).

\section{Unstructured Interviews}

The researcher carried out unstructured interviews with the National Coordinator of Climate Change in Zimbabwe, on the centrality of carbon clusters in climate change and he indicated that, carbon was so critically attached to climate change adaptation and mitigation. He stressed that companies should take advantages of 
carbon benefits that are being advertised by a variety of companies. These products are both online and off line. But his initial worry was that, Zimbabwe, with all its abundance in mineral resources, it should not wait for other countries to fund its Clean Development Mechanisms (CDM), yet it can go it alone. He also indicated that businesses in Zimbabwe needed to speak the language of climate change and venture into eco-friendly products.

\section{Document Analysis}

Document analysis is sometimes referred to as content, activity or informational analysis, for it is concerned with the classification, quantification and comparison of specified characteristics within the content of communication (Van Dalen 1983).

Hoepful (1997) asserts that another source of information that can be valuable to qualitative research is document analysis. It is concerned with exploring or analyzing documents on a particular subject or topic in order to establish certain recurring themes or features. In making use of document analysis, the researcher studied some magazines, books, pamphlets and articles on climate change to use for analysis. The researcher then used a critical discourse analysis (CDA) to study some selected texts from magazines, articles and books.

\section{Discourse Analysis}

Biber et al (2010) identify three major approaches to discourse analysis as (a) the study of language use (b) the study of linguistic structure beyond the sentence, and (c) the study of social practices and ideological assumptions that are associated with language or communication. Milner (2007) state that, when discourse is applied to language use, the goal of the researcher is to gain insight into the lexico-grammar used in the clause of a particular discourse. According to Bhatia (1993) lexico- grammatical features refer to the specific features of language in respect of lexis (words and phrases) and grammar (knowledge and use of language used in corpus). Bloomer and Wray (2006) argue that in book, newspapers and article writing, the lexical choice of writers usually reveal the ideological stand point from which they are writing. In short, one needs to understand why certain words and phrases are chosen in place of others.

\section{Critical Discourse Analysis (CDA)}

The broader Critical Discourse Analytical movements consist of several approaches among which there are similarities and differences. A brief description of the major contributors to CDA is quite appropriate in this study. Norman Fairclough is one of the outstanding figures in the fields of CDA. He regards CDA as a method of unraveling social and cultural modifications that can be used in protesting against power and control of an elite group on other people. Dellinger (1995) notes that, Critical Discourse Analysis (CDA) has made the study of language an interdisciplinary tool used by scholars from a wide range of fields such as anthropology, communication, sociology, science and linguistics. Dellinger goes on to state that CDA has an overtly political agenda as it aims at providing a better understanding of socio-economic and cultural aspects of the texts. These texts are then reproduced by socially situated speakers and writers. Fairclough (2006:104) shares the same views with Dellinger through the following: "critical discourse analysis is an inter-disciplinary approach to the study of discourse which views language as a form of social and political domination produced through text and talk." The major objective of CDA is to uncover the ideological assumptions that are hidden in written words, oral speech or pictorial communication. If one looks closely at the discourse of climate change or carbon clusters, it is clear that there are ideological stand points and issues about 'US' and 'THEM' are highly prevalent. As such, the issues about the carbon clusters and discourses were coined in the developed countries for us to implement. It is also them who initiate the debate on climate change, set the targets for compliance as well as polluting more gases (carbon) in the atmosphere. Fairclough (2000) reveals that CDA unmasks hidden meaning so as to make everything clear. For this reason, a sound knowledge of critical discourse analysis makes it possible for the readers to unravel grey areas in the discourse of carbon clusters. In this view, critical discourse analysis seeks to demystify and deconstruct the myths surrounding climate change communication.

It is important to employ CDA when analyzing the language for communicating information on carbon clusters due to the following reasons:

i) $\quad$ DA attempts to acknowledge that authentic texts are produced and consumed not in isolation but in real world contexts withal their complexities. In this view, CDA is highly context specific.

ii) $\quad \mathrm{CDA}$ is a highly integrated form of discourse analysis in that it tries to unite at least three different levels of analysis which are document, textual and social analysis. This facilitates Phillips and Jorgenson (2004)'s view that CDA is an interdisciplinary perspective which combines textual and social analysis.

iii) $\quad \mathrm{CDA}$ is very much concerned with important societal. While 'context' is meant to include not only the immediate environment in which texts are produced and interpreted but also the larger societal context including its relevant cultural, political, social inequalities, non-democratic practices and other injustices in attempting to spur readers to corrective action. 
iv) CDA does not only describe unfair social/political practices but it is critical of them. In this view, the carbon clusters, in their form and content, are regulatory in nature as well as creative and innovative in their approach.

Dellinger (1995) and Fairclough (2005)'s notions of CDA are relevant to this research, in that their core aim in critical discourse analysis is to analyze linguistic features of a text. Van Dyke (2001) is another notable pillar in CDA as he emphasizes that researchers should look at CDA as interdisciplinary, and adopts an eclectic approach towards it, using the findings of other cultures, countries and fields. Van Dyke calls this method, socio-cognitive discourse analysis, which is important in communication and interaction.

Although other forms of analyzing carbon clusters were considered, it is critical discourse analysis (CDA) that informed the basis of the whole argument of this research.

\section{A Critical Discourse Analysis of Carbon Compounds, Metaphors and their Clusters}

\section{Moral and Religious Cluster}

This cluster comprises of the following: carbon footprint, carbon sinner, carbon guilty, carbon criminal or carbon trust.

\section{Carbon Footprint}

Hensen (2006) defines carbon footprint as, the total amount of green house emissions that result directly and indirectly from your lifestyle. Carbon footprints can be measured and calculated by experts to see if a company or an organization is complying with carbon emission regulations or not. Foot prints experts are also able to show where the key carbon hot spots are within our products lifestyle.

\section{Analysis}

Literally, the concept of 'footprints' brings out the image of a pair of feet, bare feet being displayed or living out some permanent on the ground. A deeper analysis of the concept of carbon footprints unravels the issue of leaving out permanent careless and destructive marks of on the ground by foregrounding unsanctioned surface and shallow mining, unregulated industrial discharge or emissions into the atmosphere. This also includes discharging industrial waste into and chemicals into the river, throwing plastics all over, deforestation or unlocking carbon through wetland cultivation.

\section{Communicative Functions}

A combination of lexical creativity around the word carbon together with the compounding process is modeled around the morals and attitudes of people. Carbon footprints can also be metaphorical and its use is to pervade the mind and evoke elements of destructive tendencies as well as careless disregard of the law. Metaphors are effective tools of communication in providing common ground for discourses. They travel through specialized forms of communication and connect various discourses and different topics (Maasen and Weingart, 1995). Therefore the term 'carbon footprints' is aimed at correcting human behavioural activities which have contributed so much to the increase of carbon into the atmosphere. These are regulative discourses that maintain periodical checks on human activity because it is only in god that we trust but in human beings we always check. The human beings in particular, companies and organizations are all urged to take action on their carbon footprints by measuring, calculating, avoiding, reducing and offsetting carbon.

\section{Carbon Sinner}

Carbon sinner shares the same attributes with carbon footprints. A sinner is somebody who is guilty of an offence but it is the magnitude of penalty that differs. In the discourse of climate change, sinners are those countries, companies, organizations and individuals who disregard environmental laws and cause major pollutions, degradations as well as being eco-freaks. Countries who are leading polluters are the USA, China, India, Japan, Germany, United Kingdom, Brazil and France. These countries qualify to be carbon sinners. Companies like Coca Cola, Pepsi, Texaco, Shell, Total, Sasol, just to name a few are also carbon sinners. Individuals who do not walk the talk in relation to the reduction of emissions are carbon sinners as well.

\section{Analysis}

The discourse of sin has its genesis in the Garden of Eden, and it was a human being who was at the centre of sinning. It is also the discourse of sin which reminds eco-freaks and environmental plunderers that they need to change their behaviors and the way they interact with the environment. Countries like China, who, in climate change circles is described as a 'factory of the world' (http://www.iied.org/china) due to its polluting prowess. These countries have not only sinned against God alone but have sinned against the generality of 
citizens around the world, including the poor and the vulnerable. For that reason they owe these people not only an apology but also compensation for loss of lives and destruction of property.

\section{Communicative Functions}

The discourse of sin is canonical in nature as it has its roots in the bible. When God created the world, he gave stewardship of the environment to human beings. According to Mel Rees (1995), a steward is one who manages the property of another. The other word closely related to stewardship is 'dominion'. "And God said, let us make man in our image, after our likeness and let them have dominion over fish of the sea and over the earth and over every creeping thing that creepeth upon the earth" (Gen 1:26). The word 'dominion' has to do with humans receiving administrative rule over the earth from God. This word carries connotations of 'benevolent kingly care.' As a good benevolent king takes care of his subjects, humans are supposed to take of their environment.

Climate change scientists use 'sin' as a biblical allusion in an attempt to make major emitting nations feel guilty and be accountable at the same time.

\section{Dietary Cluster}

This cluster comprises of low carbon diet and carbon calories.

\section{Low Carbon diet}

It emphasizes more on people checking the amount of carbon in the foods they eat. Many food products need to be eco-friendly, they need to be quality controlled and certified by the food standards bodies to see if they comply with energy requirements standards. The certification and compliance to environmentally friendly laws would enable people to buy green. Due to the advent of inorganic farming with its genetically modified foods (GMOs), indeed the low carbon diet must be observed as some of the GMOs have long term health problems to those who consume them. It is good for the health and livelihoods of individuals.

\section{Analysis}

A critical analysis into these food stuffs reveals that, even proper knowledge of what genetically modified foods are is very much lacking in Zimbabwe and other Sub-Saharan countries. The other complex issue about the discourse of low carbon diet is the availability of the food itself. People cannot be expected to buy green especially when the food is scarce on the market; they would buy what is available and in some cases, if they don't buy what would be available they may starve. One cannot be expected to choose what type of food when they would have gone for days without eating something and when anything that looks like food is available, the we expect them to buy green, it is practically impossible. The other way out this carbon chain is to consider 'food miles' (Borchert, 2006) which provides indications regarding the amount of energy that went into growing, producing and transporting the food you eat. In this view, the advice is to 'BUY LESS' processed and packaged food, and choose locally produced foods in order to be compliant with low carbon diet.

\section{Communicative Functions}

Issues of low carbon diet and buying green are highly metaphorical in nature and that is another way scientists can be more effective in communicating by the use of metaphors. Metaphors can be used as tools of communication between various discourses. A metaphor can be considered as a mediator between different issues and discourses that may affect the action taken for or against the issues (Rogers 2002). According to Svorou (1994) metaphors are not simply stylistic devices but are a critical component of meaning generation in human communication. Turner (1988) developed the cognitive view of metaphors, which sees metaphor as a mode of conceptualizing our experiences. The cognitive views of metaphors demonstrate that metaphors are powerful cognitive tools used for the conceptualization of abstract categories. Lakoff and Turner (1989) consider metaphors as allowing us to understand one domain experience in terms of another. In this view, we are made to understand scientific issues from a linguistic perspective.

\section{Carbon Calories}

Carbon Calories share a lot of characteristics with low carbon diet as it is food driven. Grappling with the carbon impact of our food systems is not easy (http://www.climate-one.org/calories-and-carbon). Most consumers who do not have information to guide them at supermarkets are in danger of falling prey to the provenance and carbon intensity of the food they bring home. Cook (2010) advices people to 'eat-lower down the food chain-better for you, better for the planet.' It is always advisable to buy harvested foods that are natural and original and at the same time better for the environment. There is also the question of comparing the impact of grass-fed beef versus feedlot beef, or sustainably harvested beef versus domestic beef fattened in the stock yard. 


\section{Analysis}

Just like the low carbon diet, the issue of metaphorical discourse is playing a major linguistic role here. For the general populace to understand this metaphorical language, a lot of awareness and education is needed so that consumers have knowledge of the feeding processes as well as the possible impacts and dangers of inorganically harvested beef or genetically modified food products.

\section{Communicative Functions}

Metaphors of carbon calories have a direct impact on the attitudes and behaviours of the public.

Scientists use metaphors that instill fear, panic, and surprise in people. Since the discourse of food is so central and critical to the lives of human beings, the writers dwell on the use of topicalisation so that the message reaches as many people as possible as well as having a direct impact on the readership. The role of scientific metaphors as tools of communication is to shape the nature of unfolding events, which bin this view, is the eating habits as well as the buying practices. Above all, metaphors do not lose their power; as such it is a deliberate attempt to enforce compliance.

\section{The Financial Cluster}

This includes carbon marketing/trading, carbon budgets, or carbon offsetting.

Carbon markets/trading

Major polluting countries that exceed their emission targets can buy allowances from other polluting nations that are doing better than their goals. Such systems are often labeled 'cap and trade' because they operate by capping the total emissions from a group of companies or countries (which assures the overall targets will be met) and by allowing the various participants to trade carbon emission credits (which helps prioritize the lowest-cost reductions strategies).

This includes the Clean Development Mechanism (CDM) for developed countries to get credit for bank rolling projects such as reforestation or wind farms that reduce emissions in developing countries.

\section{Analysis}

Not everyone likes the CDM which allows rich nations that meet their targets to pour money into emission reducing projects I developing countries. A surface analysis would unearth the idea that this system is there to promote the pollution legacy by the ever polluting nations using the power of their money to buy other willing participants, especially in poor developing countries. A deeper analysis reveals that developing countries that are viewed as bad boys will never see any dollar for the CDM. Carbon trading is preferential and unsystematic as there are no structured formulae for implementation. Surely how many developing countries want to be paid for conserving their forests and as developing countries, how many people are into this confusing discourse of carbon marketing/trading? Although Zimbabwe may want to go green just like other countries of its nature, it is quite clear that the discourse of CDM is out of reach of many Zimbabweans and also not practically relevant to our contexts.

\section{Communicative Functions}

The system 'uses a carrot and a stick' kind of communication where the deals are done mostly according to win-lose situations.

The CDM system promotes the approaches to emissions reduction according to classes (classification) and the concept of 'Us and Them'. The system promotes labeling and insinuations by 'othering others'. This allows communication to remain hierarchical and rudimentary in nature as poor developing countries will remain indebted to the rich polluting nations and they can end up not implementing CDM projects that do not appeal to their national interests, goals and aspirations.

\section{Political Cluster}

This includes discourses like carbon neutrality, and carbon war.

\section{Carbon Neutrality}

It means that, through a transparent process of calculating emissions, reducing emissions and offsetting reduced emissions, net carbon emissions equal to zero (http://www.decc.gov.uk/en/emissions/neutrality.aspx). To achieve carbon neutrality, companies need to demonstrate their carbon management credentials. Carbon neutral has become an increasingly used term in recent years. There are also carbon neutral products (both goods and services) on the markets, including events, national and international travel journeys. 


\section{Analysis}

The discourse of carbon neutrality is about companies and organizations projecting the image of compliance and adherence to carbon management standards. In this view, companies do not want to be carrying out palliative compliant measures or over complying. They want to moderate carbon management processes for the good of business. They are in business; as such, they do not want to offend the environmental watchdogs or their business clients. They are also in politics and for that reason they always want to set the pace and maintain their supremacy over other countries. Climate change is a highly politically charged subject which has grouped countries into Annex 1 and 2 countries, as well as the BRICS.

\section{Communicative functions}

Practically, there is nothing like neutrality, especially in terms of words or language. The words that we speak, sometimes act as walls to prevent us from understanding what we need to have knowledge of. According to Fiske (1983) there is no language that is neutral, for the words that we speak, always reveal our stand point and our ideological inclinations. This means that, in as much as we may try to hide behind our words, what we say always reveal the truth or our intentions, unconsciously. The term 'neutrality' always brings out linguistic ambiguities and back grounding clear issues.

\section{Conclusion}

The thrust of this study to justify the centrality of carbon clusters in climate change adaptation and mitigation as well as their linguistic creativity. From the Critical Discourse Analysis (CDA), Document analysis and Texts analysis carried out, it has been noted that issues such as linguistic compounding and metaphors dominated the linguistic functions of the carbon clusters. For Communicative functions of carbon clusters in this carbon discourse, the tools of critical discourse analysis that have been found to be influential are canonical issues, biblical issues, ideological issues, fore grounding, back grounding, classification, topicalisation, insinuations as well as conceptualizations. Although there are some linguistic aspects that are also inherent in climate change discourse like 'collective pronouns', morph-syntactic features like alliterations, deictic features, and hedging techniques, the researcher had to narrow down to compounding and metaphors as they are prevalent in the texts and documents analyzed. The classification of carbon into clusters enabled the researcher to explore the multiplicity and indispensability of carbon as critical discourse of climate change that is both important for natural processes as well as extremely dangerous when produced into excess. The whole discourse of carbon clusters is not just an ordinary one but an ideological too as it serves the interests, not of the developing countries but of the developed countries as well. The aim of this discourse, it has been noted, is business as all these issues about carbon sinner, carbon calories, carbon markets and carbon neutrality are about new lines of business opportunities that have been unearthed because of the advent of climate change scourge. This means that, it is not always gloomy because of the shivers sent down the spines of everybody by the grim realities of climate change but new lines of business opportunities have been opened to bring smiles on the faces of companies, largely from developed countries.

It is also disheartening that, after all these clusters and metaphors as well as the dangers posed by climate change, no form of punishment has been set as a corrective measure to the polluting nations. For that reason, what can stop them from continuing to emit more carbon clearly knowing that nothing would happen to them? Most of the compounding used (carbon clusters) is out of reality or context with the majority of countries in Sub-Saharan Africa due to lack of media education and awareness in order to conscientize people about in depth knowledge of climate change issues, especially carbon clusters. The media continue to give palliative treatment or attention to tangible climate issues simply because it is not a juicy beat. Through some ambiguities in discourses of climate change, carbon clusters included, the dilemma that ordinary Zimbabweans face is that they can not understand this technical discourse or link the natural disasters to the climate change scourge.

\section{Recommendations}

(i) The majority of the people need to know how and when carbon dioxide becomes dangerous as well as how it is capable to change the climatic conditions and patterns.

(ii) Intensive awareness and education is needed so that some people even the educated ones become aware about how some climate change ambiguities can be explained. There is need to make clear these compounds, metaphors, hedging techniques and other linguistic factors so that people have less challenges in communicating them.

(iii) A symbiotic working relationship is needed especially between the business community and the media so that the industry and commerce stick to its mandate of providing quality eco-friendly products and services.

(iv) There is need for companies and organizations to come up with research initiatives and support to researchers who want to venture into unlimited frontiers of climate change research. 
(v) Knowledge about climate change communication or climate change in general need not to be commodified, instead it has to be shared for the benefit of many.

(vi) Linguists should step up their efforts of critically analyzing language so that they make grey issues clear.

\section{References}

[1]. Hensen, R. (2006) THE ROUGH GUIDE to climate change: The Symptoms. The Science. The Solutions. Rough Guides Ltd. London.

[2]. Borchert, P. (2007) AFRICA Geographic: WILDLIFE. NATURE. CONSERVATION. TRAVEL. FACTS ABOUT CLIMATE CHANGE. Africa Geographic (Pty) Ltd. Cape Town.

[3]. Crystal, D. (1991) LINGUISTICS. Harmondsworth. Penguin.

[4]. Dow and Downing (2006) Atlas of Climate Change. Rutledge. London.

[5]. Larkoff, G and Johnson, M. (1989) Metaphors we live by. Chicago: Chicago University Press.

[6]. Larkoff, G and Turner, M. (1989) More than a cool reason: A field Guide to poetic Metaphor. Chicago. Chicago University Press.

[7]. Unquerer, F. and Schmidt, H. (1996) An Introduction to Cognitive Linguistics. London. Longman.

[8]. Eubanks, P. (1999) Written Communication. Sage. Publications. 16 (2): 18-32.

[9]. Black, M. (1962) Metaphor, in Models and Methods, edited by M. Black. Ithaca, New York Rutledge.

[10]. Jorgensen, M.W. and Phillips, L. (2000) Discourse Analysis as a Theory and Method: London: Sage Publications. Hoepful, L. (1997) Research Methods in Languages. Harper and Row. London.

[11]. Milner, M.W. (2007) "Policies of Social Justice: A Visual and Verbal Analysis of Poverty in the News: Papers from the Lancaster.

[12]. Bhatia, V.K. (1993) Analyzing Genre: Language use in Professional Settings: London and New York. Longman.

[13]. Bloomer, A. and Wray, A. (2006) Projects in Linguistics: A Practical Guide to Researching Language: New York. Oxford University Press.

[14]. Fairclough, N. (2006) Language and Globalization. London and New York. Rutledge.

[15]. Fairclough, N. (2000) "Discourse and Text Linguistics and Intertextual Analysis. Within Discourse Analysis" Discourse and Society. Vol. 3 No3. 193-217.

[16]. Fairclough, N. (2000) "Discourse and Text Linguistics and Intertextual Analysis. Within Discourse Analysis" Discourse and Society. Vol. 3 No3. 193-217.

[17]. http://www.iied.org/china Accessed on 2012/07/04

[18]. Mel Rees (1995) Biblical Principles for living and Giving (Atlanta, Georgia: JA. Thomas and Associates, 1995), v9.

[19]. Svorou, S. (1994) The Grammar Space. Philadelphia. John Benjamin Publishing Company.

[20]. http://www.climate-one.org/calories-and-carbon Accessed on 2012/07/05.

[21]. http://www.decc.gov.uk/en/emissions/nuetrality.aspx Accessed on 2012/07/05. 